\title{
NOTAS SOBRE ENSINO DE HISTÓRIA DA EDUCAÇÃO NO CURSO DE PEDAGOGIA DA UEPG (1963-2012)
}

\author{
COMMENTS ON THE TEACHING OF THE HISTORY OF EDUCATION IN THE \\ TEACHING COURSE AT UEPG (1963-2012)
}

Névio de Campos ${ }^{1}$

\begin{abstract}
Resumo: Este artigo objetiva realizar um mapeamento do ensino de História da Educação no Curso de Pedagogia da Universidade Estadual de Ponta Grossa, no período circunscrito entre 1963-2012. Apoia-se nos relatórios da Faculdade de Filosofia, Ciências e Letras, nos relatórios e no catálogo geral da Universidade Estadual de Ponta Grossa e nos programas de disciplinas, privilegiando um olhar acerca das denominações e carga horária, ementas e programas, assim como referências das obras utilizadas. A partir dessas fontes e em diálogo com a produção acadêmica é possível sustentar que houve forte continuidade de conteúdos atrelados aos tradicionais recortes temporais da história ocidental (Antiguidade, Idade Média, Períodos Moderno e Contemporâneo) e à tradicional divisão política brasileira (Colônia, Império e República), sem deixar de aparecer alguma alteração com a inclusão de temáticas específicas da educação, como, feminização do magistério, criança e infância, formação de professores. Além disso, observa-se uma presença marcante dos tradicionais manuais de História da Educação, sofrendo grande diminuição a partir do final dos anos de 1990 e início dos anos 2000, o que indica certa aproximação entre a organização do ensino e o campo de pesquisa em História da Educação.
\end{abstract}

Palavras-chave: História da educação. Ensino de história da educação. Curso de pedagogia. Universidade Estadual de Ponta Grossa.

\begin{abstract}
The aim of this article is to map out the teaching of History of Education in the Teaching Course at the State University of Ponta Grossa, from 1963 to 2012. This study bases itself on the reports from the Faculty of Philosophy, Sciences and Languages, on the reports and catalogue of the State University of Ponta Grossa and on the subjects, highlighting the denominations, hour schedule, syllabus and programs as well as a reference of the books used. Based on these sources and dialogues with the academic production it is possible to argue that there has been a strong continuity of contents related to traditional temporal cuts of western history (Ancient History, Middle Ages, Modern and Contemporary Periods) and to the traditional division of Brazilian politics (the Colonial Period, Empire and Republic), while also showing changes which included specific subjects in education such as feminization of the degree in primary teaching and learning, child

\footnotetext{
1 Pós-doutor em sociologia dos intelectuais (EHESS), pós-doutor em história intelectual (UFPR), doutor em educação (UFPR), professor no Programa de Pós-Graduação em Educação da Universidade Estadual de Ponta Grossa, pesquisador produtividade CNPq. Email: ndoutorado@yahoo.com.br.
} 
and childhood, teacher education. In addition, the use of traditional manuals on the History of Education decrease significantly in the late 1990s and early 2000, which shows an approach between the organization of teaching and field of research in the History of Education.

Key words: History of education. Teaching of history of education. Teaching degree. State University of Ponta Grossa.

\section{Introdução}

O objetivo deste texto é discutir a forma de organização do ensino de História da Educação no Curso de Pedagogia da Universidade Estadual de Ponta Grossa (UEPG). Inscreve-se no debate sobre o problema do ensino de História da Educação, dialogando com estudos que têm no seu horizonte a produção de conhecimento acerca do ensino dessa área em diferentes instituições universitárias brasileiras, cuja presença obrigatória se reporta ao Decreto-lei que estabeleceu esse curso de graduação (1939). ${ }^{2}$

A produção de uma análise do ensino de História da Educação na UEPG é uma tarefa difícil e complexa, pois remonta ao período de constituição do Curso de Pedagogia, no ano de 1962. O recuo ao começo da década de 1960 é importante para retratar determinadas características do ensino dessa disciplina, haja vista que esteve presente de modo contínuo na estrutura curricular desse curso. A ideia

\footnotetext{
${ }^{2}$ Este artigo aparece num contexto em que "pelo menos, há duas décadas o interesse dos pesquisadores de história da educação tem recaído, com significativa frequência, sobre os aspectos e condicionantes em que se tem processado o ensino dessa disciplina escolar" (MENEZES, 2014, p. 260). Essa observação de Roni Menezes pode ser observada pela recorrência desse tipo de pesquisa, uma vez que muitos autores têm estudado esse tema, como, por exemplo, Acostas (2017), Silva e Favaro (2014), Mendez (2014), Menezes (2014), Pasche (2014), Valle (2012), Souza e Ribeiro (2012), Faria Filho e Rodrigues (2003), Campos (2011), Gatti Junior (2006, 2008, 2011), Araújo, Ribeiro e Souza (2011), Quadros (2006, 2011), Dallabrida (2011), Queiroz (2011), Carvalho (2011), Warde (1990, 1998, 2011), Bencostta e Vidal (2010), Bontempi Junior (2007), Vieira e Roballo (2007), Morais, Portes e Arruda (2006), Nunes (1996, 2006), Stephanou (2006), Tambara (2006), Santiago (2006), Bastos, Busnello e Lemos (2006), Esquinsani (2006), Orth (2006), Werle e Corsetti (2006), Azevedo, Ismério e Silveira (2006), Saviani (2005a, 2005b), Bastos, Bencostta e Cunha (2004), Faria Filho e Rodrigues (2003), Vidal e Faria Filho (2003). Há muita produção acerca do ensino de História da Educação. Em busca no Portal de Periódicos CAPES/MEC, pelo descritor “ensino de história da educação”, identifica-se um grande contingente de artigos publicados. Aqui indicamos apenas uma parte da produção existente. Sem dúvida que esse descritor se apresenta amplo. No entanto, justifica-se pelo objetivo proposto por nosso artigo, restando a outras pesquisas recortes mais específicos, como o uso de manuais no ensino de história da educação, a formação dos professores dessa disciplina, os conteúdos arrolados na organização do ensino, etc.
} 
central é aludir certos aspectos, notadamente as denominações e a carga horária, assim como a organização das ementas e dos programas, buscando apresentar uma visão geral da estrutura dessa disciplina, sem deixar de dialogar com as experiências de seu ensino em outras universidades brasileiras.

Assim sendo, esta narrativa elege três elementos: 1) denominações e carga horária da disciplina; 2) ementas e programas; 3 ) referências das obras utilizadas. Diante dessa escolha, compartilhamos da assertiva de que "uma perspectiva de apreensão e compreensão das disciplinas acadêmicas e curriculares, que parece ser reveladora da sua configuração nos referidos cursos, pode ser operada [...] pelos programas de ensino" (RODRIGUES, 2011, p. 146). Além disso, destaca Rodrigues (2011, p. 146-147), "[...] podem ser abordados os aspectos curriculares, as características institucionais e acadêmicas e as referências bibliográficas". Desse modo, a organização deste texto privilegia uma discussão sobre o ensino de História da Educação no Curso de Pedagogia a fim de apresentar um quadro geral da sua experiência no currículo de formação do estudante de Pedagogia da UEPG.

\section{Denominações e carga horária}

Entre 1963 (primeira oferta da disciplina) e 2012 (última reforma curricular) houve alterações do seu lugar no currículo do Curso de Pedagogia da UEPG. Este Curso iniciou suas aulas no ano de 1962. No entanto, História da Educação foi ofertada pela primeira vez em 1963. No quadro 1 constam informações referentes à denominação da disciplina e carga horária. Nele, podemos perceber dados a respeito das denominações da disciplina que se assemelham a outras instituições, como assinala o estudo de Luciano Faria Filho e José Roberto Gomes Rodrigues (2003) sobre quatro universidades de Minas Gerais. Prevalece a denominação História da Educação, com indicação de alguma ordem numérica, como se observa a partir de 1973. Essa característica circunscreve grande parte das experiências das universidades brasileiras, pois "essa denominação é a mais recorrente dentre os cursos pesquisados, identificada em 72 disciplinas" (BORGES; GATTI JUNIOR, 2010, p. 27). Além disso, está presente o recorte característico em História da Educação Brasileira, tendência mais recente na UEPG (1989). Nesse aspecto, tem 
relação com outras instituições brasileiras, embora com uma tendência menor, pois conforme revelam Bruno Borges e Gatti Junior (2010, p. 27), "Composta História da Educação Brasileira, [está] presente em 11 disciplinas ou História da Educação Geral e no Brasil em 10 disciplinas".

\begin{tabular}{|c|c|c|c|}
\hline ANO & NOME DA DISCIPLINA & CARGA HORÁRIA & SÉRIE DO CURSO \\
\hline 1963 & História da Educação & 64 & $2^{a}$. \\
\hline 1964 & História da Educação & 94 & $2^{a}$. \\
\hline 1965 & História da Educação & 100 & $4^{a}$. \\
\hline 1966 & História da Educação & 100 & $3 a$. \\
\hline 1966 & História da Educação & 102 & $4^{a}$. \\
\hline 1973 & História da Educação I & 75 & $1^{a}$. \\
\hline 1973 & História da Educação II & 75 & $2^{a}$. \\
\hline 1973 & História da Educação III & 75 & $3 a$. \\
\hline 1979 & História da Educação I & 60 & $1^{a}$. \\
\hline 1979 & História da Educação II & 60 & $2^{a}$. \\
\hline 1979 & História da Educação III & 60 & $3 a$. \\
\hline 1979 & História da Educação IV & 45 & $4^{a}$. \\
\hline 1989 & História da Educação (HE) & 138 & $1 \mathrm{a}$. \\
\hline 1989 & $\begin{array}{l}\begin{array}{l}\text { História da } \\
(\mathrm{HEB})\end{array}\end{array}$ & 102 & $2^{a}$. \\
\hline 2006 & História da Educação (HE) & 68 & $1^{a}$. \\
\hline 2006 & $\begin{array}{l}\begin{array}{l}\text { História da Educação } \\
(\text { HEB })\end{array} \\
\end{array}$ & 102 & $2^{\mathrm{a}}$. \\
\hline 2012 & História da Educação (HE) & 68 & $1^{a}$. \\
\hline 2012 & 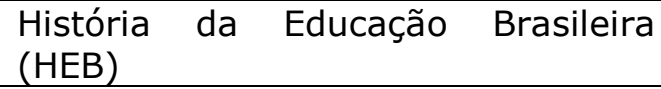 & 102 & $2^{\mathrm{a}}$. \\
\hline
\end{tabular}

Fonte: O autor (2020).

A denominação e a carga horária sofreram alterações entre 1963 e 2012. Em 1963, constava na segunda série do Curso de Pedagogia, com carga horária prevista de 64 horas. $^{3}$ No relatório referente ao ano de 1965, especificamente no mapa demonstrativo das aulas, esta disciplina constava na quarta série, com carga

\footnotetext{
${ }^{3}$ Conforme relatório das atividades da Faculdade de Filosofia, Ciências e Letras de Ponta Grossa, "durante o ano de 1963, apenas um concurso realizou-se para o preenchimento de cátedra - o referente à História da Educação". Além disso, o referido relatório informa que "foi escolhido o professor licenciado por esta Faculdade Orlando Cwiertnia, o qual, após, alguns meses de prática, demonstrou estar em perfeitas condições para o exercício do magistério superior". Pelo que consta no relatório de 1964, apenas no decorrer deste ano, "o Governo do Estado do Paraná, através, da Secretaria de Educação e Cultura, nomeou por Decreto o professor Orlando Cwiertnia, que submeteu-se a concurso no ano anterior de 1963, para reger a cadeira de História da Educação, do curso de Pedagogia" (UEPG, 1964, p. 36). Pelo que observamos no relatório, a posse deste professor ocorreu em 18 de novembro de 1964. No entanto, ele estava à frente desta disciplina antes da tomada de posse, provavelmente na condição de contratado temporariamente. No relatório da Faculdade de Filosofia, Ciências e Letras de Ponta Grossa do ano de 1975 consta que Professor Orlando Cwiertnia possui licenciatura em Geografia e História pela Faculdade de Filosofia, Ciências e Letras de Ponta Grossa, em 1961. Além disso, indica-se que realizou Curso de Extensão e Estágio de Especialização em História da Educação e Didática do Ensino Superior na Universidade Federal do Paraná, em 1967 (UEPG, 1975, p. 174). Professor Orlando aposentou-se no ano de 1999.
} 
horária prevista de 100 horas, deixando de figurar na segunda série, em atendimento à reforma que passou a vigorar a partir desse ano e em adequação do Parecer CFE 251/62. No relatório do ano seguinte, localizamos a presença dela nas terceira e quarta séries, com carga horária prevista de 100 e 102 horas, respectivamente ${ }^{4}$. No mapa de 1966, aparece nas duas últimas séries, permitindo afirmar que passou a se fazer presente na terceira e quarta séries, pois não estava determinada em norma qual série deveria estar. No período de 1963 até 1972, integrava o currículo de Pedagogia nas terceira e quarta séries, sob a denominação de História da Educação, totalizando aproximadamente 200 horas, divididas nas duas séries. ${ }^{5}$

Em 1972, ocorreu a primeira reforma curricular, após o início do curso. Naquele momento, houve mudança na sua denominação. História da Educação passou a ser estratificada em: História da Educação I, II, III, com carga horária de 75 horas cada uma, totalizando 225 horas. ${ }^{6}$ Essa organização manteve-se até 1978. A partir de 1979, identificamos outra organização nas denominações, sem alteração na carga horária total: História da Educação I, II, III e IV. As três primeiras tinham 60 horas em cada uma delas. A última possuía carga horária de 45 horas. Essa organização foi alterada na reforma de 1989, quando História da Educação, com 136 horas, substituiu História da Educação I e II. E História da Educação Brasileira, com 102 horas, ocupou o lugar de História da Educação III e

\footnotetext{
${ }^{4}$ No rol de disciplinas e suas respectivas cargas horárias do Curso de Pedagogia da UEPG se observa uma distribuição bastante irregular. Essa situação vai aparecer de modo padronizado a partir de 1973, embora com a reforma que passou a vigorar a partir de 1965 a carga horária parece indicar uma certa regularidade. Mais informações consultar a tese de Audrey Pietrobelli de Souza (2017) intitulada Trajetória da Psicologia da Educação no Curso de Pedagogia da UEPG (1962-2012): conformação e consolidação do campo de conhecimento.

5

O Curso de Pedagogia tem sua primeira regulamentação em 1939 com a Decreto-lei n. 1.190/39, notadamente no Artigo 19 da Seção XI que determinava a obrigatoriedade de História da Educação e sua inclusão na segunda e terceira séries. A partir do Parecer CFE 251/62 foi mantida sua obrigatoriedade, sem definir a série em que deveria ser incluída. Mais dois marcos do Curso de Pedagogia merecem ser mencionados: Parecer CFE 252/69 e Resolução CNE n. 1, de 10/4/2006, sendo mantida a obrigatoriedade de História da Educação, sem definir série e carga horária (ou seja, caberia à universidade e aos referidos colegiados tais proposições). Para mais informações, consultar o livro Curso de Pedagogia no Brasil - história e formação com pedagogos, de Giseli Barreto da Cruz (2011), bem como o artigo Pedagogia: o espaço da educação na universidade, escrito por Dermeval Saviani (2007).

${ }^{6}$ Conforme Audrey Pietrobelli de Souza (2017, p. 63), "o processo de reestruturação de 1972 foi mobilizado para atender às exigências do Parecer CFE 252/69, que fixava o currículo mínimo e a duração de 2.200 horas para os Cursos de Pedagogia do país, as quais deveria ser distribuídas em três anos e um máximo de sete anos letivos". Mais informações consultar a tese de Audrey Pietrobelli de Souza (2017), especialmente o item 1.3 do primeiro capítulo.
} 
IV. Mais reformas foram feitas, entre 1989 e 2006, mas em nenhuma delas houve alteração no nome e na sua carga horária. Entretanto, na reestruturação curricular de 2006 ocorreu mudança, passando de 138 para 68 horas em História da Educação. Em relação à História da Educação Brasileira não houve alteração de carga horária, mantendo-se 102 horas.

Esse mapa geral referente às denominações e a carga horária ainda será objeto de discussão no item seguinte, principalmente no momento de exposição da bibliografia utilizada. Assim mesmo, é importante assinalar que a regulamentação externa previa carga horária mínima do curso e disciplinas obrigatórias e facultativas, restando aos responsáveis dos órgãos deliberativos definir a estrutura nas suas respectivas instituições. Dessa maneira, a partir das fontes que utilizamos é possível observar os resultados, sem acessar os processos que poderiam evidenciar as disputas entre as áreas do conhecimento (disciplinas). Ainda assim, podemos dizer que no início do curso, História da Educação totalizava 158 horas, passando a 200 horas depois de 1965. A partir da reformulação de 1972, a área foi distribuída em três disciplinas (I, II, III), totalizando 225 horas. Em 1979 houve reformulação do currículo do curso, quando História da Educação sofreu alteração e se fez presente em todas as séries, mantendo-se as 225 horas. A partir de 1990 a nomenclatura foi alterada, assim como a carga horária total que chegou a 240 horas. A partir da reforma de 2006, diminuiu para o total de 170 horas, representando uma redução de 29,17\%. Esse corte da carga horária está associado às regulamentações, principalmente às normas produzidas no início do século XXI, quando novas disciplinas se tornaram obrigatórias e um conjunto de exigência referente ao papel da Pedagogia entra em vigor (SAVIANI, 2007), além das próprias disputas internas de cada instituição que promove suas reformas (SOUZA, 2017).

As novas demandas legais estão ligadas aos debates acadêmicos e políticos que envolvem um curso de formação de especialista em Pedagogia ou de professor. Nesse sentido, este item procurou mostrar a configuração disciplinar de História da Educação no âmbito do Curso de Pedagogia da UEPG, sem deixar de, implicitamente, chamar atenção ao conjunto de aspectos que condiciona a institucionalização das diferentes áreas no espaço universitário. Esse aspecto está vinculado, em termos gerais, ao debate e confronto em torno das concepções de 
formação geral/específica, atualmente denominadas de formação básica geral e formação específica profissional.

\section{Ementas e programas}

Ao analisar os relatórios da Faculdade de Filosofia, Ciências e Letras de Ponta Grossa não foram localizados ementas e programas de História da Educação dos anos de 1963 e 1964. Observamos que ela constava no mapa de aulas da segunda série do curso de Pedagogia. No relatório referente ao ano de 1965, encontramos os dois programas, sendo da terceira série e outro da quarta série, sem indicação de ementas. ${ }^{7}$

Se não havia uma ementa, tal como conhecemos hoje, existia uma imensa lista de conteúdos que podem indicar as pretensões dessa disciplina. A proposta que se dirigia a terceira série estava dividida em introdução e mais quatro unidades, assim distribuídas: Introdução - Educação, Pedagogia, importância de seu conhecimento para o educador. Unidade I - Tradicionalismo Pedagógico (educação primitiva; educação hindu; educação chinesa; educação egípcia; educação hebraica; educação persa); Unidade II - Humanismo Pedagógico Clássico (educação grega; educação romana); Unidade III - Cristianismo Pedagógico (educação agostiniana; educação patrística; educação monástica; educação escolástica); Unidade IV - Medievalismo Pedagógico Leigo (educação feudal da cavalaria; educação muçulmana). Na sequência do Programa consta a seguinte observação: "em cada capítulo, serão estudados os aspectos da vida social, cultural, religiosa, política, econômica, além dos educadores práticos e teóricos, suas influências sobre os métodos pedagógicos e sobre a cultura universal" (UEPG, 1965). É possível perceber que para a carga horária aproximada de 100 horas, estava prevista a incursão aos períodos da História Antiga e Idade Média.

Para a quarta série estava previsto o seguinte planejamento: Unidade I - O novo humanismo pedagógico (educação humanista da renascença; educação da

\footnotetext{
${ }^{7}$ embora suas discussões ocorressem nos órgãos colegiados do Curso e na Congregação da Faculdade de Filosofia, Ciências e Letras de Ponta Grossa (até 1970), e no Setor do Conhecimento e divisões ligadas à Pró-Reitoria de Graduação, depois de 1970 com a criação da UEPG. A UEPG foi criada em 1970, a partir de junção de várias faculdades, entre elas a Faculdade de Filosofia, Ciências e Letras de Ponta Grossa, fundada em 1949. Mais informações consultar Névio de Campos e Eliezer Felix de Souza (2016).
} 
Reforma e da Contrarreforma religiosa); Unidade II - O naturalismo pedagógico (realismo pedagógico; conceito disciplinar de educação; pietismo e a nova educação cristã realista; racionalismo iluminista e fisiocracia; naturalismo de Rousseau; educação revolucionária; tendência psicológica em educação; tendência científica em educação); Unidade III - O novo naturalismo pedagógico (tendência individualista em educação; tendência nacional-socialista em educação; tendência pragmatista e técnica); Unidade IV - (Educação contemporânea e suas tendências; evolução da educação no Brasil). Após a sistematização das unidades e conteúdos, observa-se que "em cada capítulo serão analisados todos os aspectos que caracterizam a época, tendências e métodos pedagógicos, bem como os vultos que, direta ou indiretamente, exerceram influência sobre a educação" (UEPG, 1965). Nesta organização estava contemplada a história da educação do período moderno ao contexto contemporâneo, o que indica que seu ensino estava atrelado à uma concepção enciclopédica de história, modelo prefigurado nos manuais, como veremos mais adiante.

No programa de 1966, as unidades são mais extensas e com maior detalhamento. Em termos gerais, a organização destinada à terceira série continha oito unidades, iniciando com as origens da educação entre os povos primitivos e chegando ao Renascimento e à fase humanística na educação. Ao comparar com plano do ano anterior, identifica-se a separação em unidades da educação entre gregos e romanos, a inclusão da unidade origens da educação entre os povos primitivos, o deslocamento do item Renascimento e educação humanista, e especificação do item caráter e espírito da educação medieval (o escolasticismo e as universidades). Estava presente a pretensão de uma história total, englobando os mais diversos contextos. O que surge de novo é a nota introdutória do programa: "Introdução: importância, relações e objetivos da História da Educação, Educação e concepções filosóficas, através da História, Os períodos característicos da História da Educação" (UEPG, 1967, p. 97). Aparece uma preocupação em justificar a sistematização de um programa de ensino de História da Educação, aspecto que indica a necessidade dessa área mostrar a relação do presente com o passado (espaço de experiência) e com o futuro (horizontes de expectativa). Essa tarefa que acompanha a escrita e o ensino da história pode ser melhor entendida 
nas discussões do livro Futuro-passado de Reinhart Koselleck (2006). No rol dos conteúdos podemos observar o pressuposto que o espaço de experiência da educação estaria no conhecimento global do que estava circunscrito aos períodos Antigo, Medieval, Moderno e Contemporâneo. ${ }^{8}$

Já História da Educação, destinada à quarta série, previa dez unidades, contemplando discussão desde as reformas religiosas europeia até história do Brasil. A introdução do programa prescrevia a discussão dos "mais graves problemas da educação contemporânea à luz da sua evolução histórica" (UEPG, 1967, p. 97). Além disso, merece destaque o detalhamento de aspectos referentes ao movimento filosófico e pedagógico da modernidade: a Companhia de Jesus e os Jansenistas; tendência realista em educação (as fases do Realismo; Comenius); educação no conceito disciplinar (John Locke); o racionalismo naturalista (Rousseau e seus discípulos); tendência psicológica em educação (Pestalozzi, Herbart e Froebel); a educação de caráter nacional no século XIX (influência da Revolução Francesa); o progresso científico e a educação no século XIX (Comte, Spencer, etc.); tendência democrática na educação do século XX (o movimento das escolas novas); tendências ecléticas da educação contemporânea (visão sintética da história da educação no Brasil). Após a reforma de 1965, ganha visibilidade uma parte da história da educação brasileira, mantendo-se a divisão dos quatro períodos da história (Antiga, Medieval, Moderna e Contemporânea) e a prevalência da história das ideias pedagógicas. O espaço de experiência estava contido também na história da educação brasileira, notadamente naquela circunscrita a partir da chegada dos europeus à América portuguesa.

No programa de 1971 observamos alteração no modo de discriminação das unidades e conteúdos. No mesmo programa, constam os conteúdos das terceira e quarta séries. Vale destacar, a unidade que trata das bases da educação de um povo (sua estrutura social e política; sua estrutura econômica; o direito, a moral); na unidade que retrata as reformas religiosas e a educação, há um item específico denominado os jesuítas e o seu papel na educação do Brasil Colonial; a unidade que discutia a Revolução Francesa ampliou-se ao incorporar os direitos universais do homem e seus reflexos sobre a educação e democracia; na unidade

\footnotetext{
${ }^{8}$ É importante destacar livros que discutem os critérios de periodização, como, por exemplo: Os antigos, o passado e o presente de François Hartog (2003); A história pode ser dividida em pedaços? de Jacques Le Goff (2014).
} 
nacionalismo como teoria político-social e seus reflexos sobre a educação abriu-se discussão a respeito do que se classificou como regimes autoritários, onde o programa da disciplina incluía Nazismo, Fascismo e Comunismo soviético. Por fim, na última unidade, aparece uma descrição mais detalhada da história da educação brasileira: "Educação no Brasil - evolução, história e resultados. Sociedade colonial e educação. A educação no Império e na República. Os problemas da educação brasileira, em face do atual desenvolvimento" (UEPG, 1972, p. 199).

A partir de 1973 houve alteração na organização da disciplina, pois passou a integrar três séries. Conforme Catálogo Geral da UEPG (1973, p. 93), a ementa de História da Educação I previa fundamentos e correlação com outras disciplinas pedagógicas. Educação na antiguidade oriental e clássica. Cristianismo e educação. Educação na Idade Média. Já História da Educação II contemplava Renascimento e educação. Reformas religiosas e educação. Realismo em educação. Educação nos séculos XVII e XVIII. Por fim, em História da Educação III constava: condições subjacentes da educação no século XIX. Educação no século XIX e XX. Educação atual: tendências. Educação brasileira, no contexto geral do mundo 9 .

Pelo exposto nos parágrafos que descrevem os conteúdos, observa-se uma tendência semelhante a indicada por José Gomes Rodrigues (2011, p. 152): "[...] os conteúdos da História da Educação se diversificam nas formas de apresentação, na definição espaço-temporal, bem como nas possibilidades de abordagem dos temas, que Ihes são correspondentes". Além disso, outro elemento recorrente é: "Quanto mais a carga horária se apresenta reduzida, mais o conteúdo estabelecido pelo ementário parece ampliar-se, alargando-se nos espaços e tempos abordados" (RODRIGUES, 2011, p. 154). Dessa observação merece destaque a semelhança entre os dados da pesquisa de Rodrigues e a experiência de ensino na UEPG, em particular quando assinala:

Ao tratar da educação ocidental, muitas vezes, os conteúdos são especificados nas unidades de ensino, contemplando a história da civilização humana nos momentos históricos mais diferenciados, inclusive a própria história do homem desde os

\footnotetext{
${ }^{9}$ Essas ementas mantiveram-se até 1979.
} 
primórdios da civilização até a contemporaneidade. (RODRIGUES, 2011, p. 154).

Em geral, os programas de ensino de 1975 expressam continuidade dos modelos empregados nos anos anteriores. O que merece destaque é a inclusão das referências utilizadas nos programas. Em História da Educação I não consta o item referências. Na II consta em bibliografia a seguinte descrição: "todos os livros de História da Educação e da Pedagogia; todos os livros de Filosofia da Educação; Livros especialmente indicados de História da Civilização; Obras paralelas; Publicações especializadas" (UEPG, 1975). Na III constam apenas os nomes dos autores, com exceção de História da Educação e da Pedagogia de Paul Monroe. No programa de História da Educação I de 1977, identificamos um item introdutório que tratava dos seguintes aspectos: "Conceito de história da educação importância; objeto e objetivos; fontes de estudo; metodologia; classificação; funções" (UEPG, 1977).

No programa de 1979 é possível identificar a descrição de autores e obras nas referências, como vemos no quadro 2.

Quadro 2 - Referências indicadas nos Programas (1979)
\begin{tabular}{|l|l|}
\hline AUTOR & OBRAS \\
\hline Theobaldo Miranda Santos & Noções de História da Educação. \\
\hline Paul Monroe & História da Educação \\
\hline Lorenzo Luzuriaga & História da Educação e da Pedagogia \\
\hline Francisco Larroyo & História Geral da Pedagogia \\
\hline Maria da Glória Rosa & História da Educação através de textos \\
\hline Renê Hubert & História da Educação \\
\hline José Antonio Tobias & História da Educação Brasileira \\
\hline Louis Riboulet & História da Pedagogia \\
\hline Madres Peeters e Cooman & Pequena História da Educação \\
\hline Lorenzo Luzuriaga & História da Educação Pública \\
\hline
\end{tabular}

Fonte: O autor (2020).

Da descrição acima é importante assinalar a predominância da história da educação geral em relação à história da educação brasileira, muito embora constasse o manual de José Tobias. Essa nota é sustentada pelo estudo de José Carlos Araújo, Betânia Ribeiro e Sauloéber Souza (2011) acerca de dez manuais, publicados entre 1914 e 1972, que trataram da educação brasileira. Nesse estudo, os autores afirmam: "o que é marcante, numa visão de conjunto, é a perspectiva subalterna que ocupa a história da educação brasileira em referência à história 
geral da educação ou à história da educação ocidental" (ARAÚJO; RIBEIRO; SOUZA, 2011, p. 107).

Em 1979, houve reorganização da disciplina. É possível identificar que, entre 1979 e 1989, as ementas se mantiveram. Conforme registro no Catálogo Geral da UEPG (1980, p. 275), História da Educação I tinha a seguinte organização: História da Educação: fontes, objetivos e conceituação. Origens da educação. Educação na antiguidade oriental. Educação humanista das civilizações clássicas, abrangendo: principais pedagogos e suas influências. Análise dos sistemas educacionais e suas consequências. Na II consta: o cristianismo e suas influências sobre a educação. Educação na Idade Média. O humanismo renascentista e a educação. Reformas religiosas e educação. Início da educação moderna: o realismo pedagógico. Educação nos séculos XVI e XVII. E a III previa, Educação e pedagogia no século XVIII. As grandes correntes da pedagogia contemporânea, analisadas em suas origens histórico-culturais. Pedagogia do século XIX. Pedagogia do século XX.

Apenas localizamos a ementa de História da Educação IV no relatório do Catálogo Geral da UEPG de 1985. Percebemos que essa disciplina prescrevia em sua ementa o seguinte: fatores subjacentes da educação contemporânea: fatores políticos, científicos, filosóficos e culturais. A educação brasileira dentro do contexto histórico (UEPG, 1985, p. 310). Ao comparar com as ementas anteriores a 1970, na III identifica-se grande mudança, pois passou a se enfatizar a história da pedagogia. Por outro lado, a ementa da IV consistia em uma parte da III que existia até 1979.

No relatório do Setor de Ciências Humanas, Letras e Artes de 1987, localizamos os programas de História da Educação, exceto da II. Em geral, os programas das três que localizamos seguem os modelos identificados nos planos anteriores. Destaca-se da I: conceito de História da Educação - objetos e objetivos. Fontes de estudo. Importância da História da Educação. O programa da IV, cuja ementa previa ensino da educação brasileira, discriminava os seguintes conteúdos: 1. Os fatores subjacentes da educação contemporânea (a educação e a problemática do mundo atual; os fatores políticos, sociais, filosófico-culturais e suas influências sobre a educação universal e brasileira). 2. As múltiplas tendências da educação no século XX (os movimentos político-sociais; nacionalismo, totalitarismo, a democracia e a educação no século $X X$; a educação 
no país do terceiro mundo). 3. O movimento da escola nova (as bases científicas, políticas, sociais e filosóficas; os grandes nomes da educação do século XX, suas ideias e influências).

Nos programas de 1987 consta a descrição das seguintes obras:

\begin{tabular}{|c|c|}
\hline AUTOR & OBRAS \\
\hline Theobaldo Miranda Santos & $\begin{array}{l}\text { Noções de História da Educação - HE I, } \\
\text { III e IV }\end{array}$ \\
\hline Paul Monroe & História da Educação - HE I, III e IV \\
\hline Lorenzo Luzuriaga & $\begin{array}{l}\text { História da Educação e da Pedagogia - } \\
\text { HE I, III e IV }\end{array}$ \\
\hline Francisco Larroyo & $\begin{array}{l}\text { História Geral da Pedagogia (10. Vol.)- } \\
\text { HE IV }\end{array}$ \\
\hline Maria da Glória Rosa & $\begin{array}{l}\text { História da Educação através de textos - } \\
\text { HE I, III e IV }\end{array}$ \\
\hline Renê Hubert & História da Pedagogia HE III \\
\hline Joaquim Henrique Lauer & História da Educação - HE I e IV \\
\hline N. Abbagnano e A. Visalberghi & História da Educação - HE I e IV \\
\hline Frederick Meyer & $\begin{array}{l}\text { História do pensamento educacional - HE } \\
\text { I e IV }\end{array}$ \\
\hline
\end{tabular}

Fonte: O autor (2020).

Em 1990, passou a vigorar o novo currículo, no qual a disciplina sofreu alteração em sua denominação. Em História da Educação consta: Conceito de História da Educação. A educação e contexto social. As origens da educação. Educação na antiguidade oriental. Educação na antiguidade clássica. Educação medieval. Influências do cristianismo sobre a cultura e a educação. A escolástica e as universidades. Educação moderna: visão global (UEPG, 1990, p. 175). Em História da Educação Brasileira aparece: o contexto histórico universal da educação moderna e contemporânea. Fatores subjacentes da educação contemporânea, repercussões no Brasil. Evolução da educação brasileira no contexto histórico universal. Brasil-Colônia, Império e República (UEPG, 1990, p. 175). Nos programas localizados não há indicação das referências utilizadas. No item bibliografia básica ou complementar consta que "a bibliografia será dada a conhecer aos alunos da sala de aula, a cada início de período letivo, dado que as edições dos livros didáticos são dinâmicas" (UEPG, 1991). Embora não apareçam as referências bibliográficas, os conteúdos indicados guardam forte relação com os sumários dos tradicionais manuais de História da Educação.

Dois aspectos destacam-se. Por um lado, a inclusão da disciplina História da Educação Brasileira. Por outro, a ementa consubstancia questões afetas à história 
moderna e contemporânea ocidental e ao Brasil. No programa identificamos sete itens no rol de conteúdos, dos quais quatro tratam de temas atinentes à Europa, dois tratam de aspectos gerais e do Brasil e três retratam especificamente a educação brasileira (Colônia, Império e República). A periodização da história política ganha evidência, condição semelhante ao que indica o estudo de Faria Filho e Gomes Rodrigues (2003).

Essa estrutura de ementa foi alterada no ano de 1997, quando História da Educação ficou assim definida: conceito de História da Educação. As origens da educação. Educação na antiguidade oriental. Educação na antiguidade clássica. Educação medieval.

Educação moderna (UEPG, 1997, p. 272). ${ }^{10}$ E História da Educação Brasileira ficou: o pacto colonial e a educação jesuítica. Revolução Industrial e Francesa. Educação no Império. Brasil republicano: relações internacionais, industrialização, urbanização, expansão da rede pública de ensino, reformas e concepções de educação. Cidadão e os desafios da democratização social e escolar (UEPG, 1997, p. 272$)^{11}$. O programa de ensino de História da Educação segue o mesmo modelo

\footnotetext{
${ }^{10}$ Em 1998, houve o segundo concurso público para História da Educação, sendo aprovada a professora Cleide Aparecida Farias Rodrigues. Professora Cleide Rodrigues já estava na UEPG, desde 1971. Porém, aposentou-se e voltou após aprovação. Anteriormente, atuava na área de Sociologia. Ela é formada em Pedagogia (1969) pela UEPG, especialista em Métodos e Técnicas de Ensino (1974) pela UFPR e mestrado pela UEPG com a dissertação intitulada "Caminhos e (des) caminhos da política educacional paranaense: a articulação entre $1^{\circ}$. e o $3^{\circ}$. Graus de ensino e a educação continuada de docentes" (1997), sob orientação de Lilian Wachowicz. Após aprovação em concurso público para História da Educação, ela aparece nos relatórios trabalhando com essa disciplina. Porém, com poucas aulas, em razão de estar envolvida com várias atividades administrativas na UEPG. Em 1998, por exemplo, no relatório consta que ela trabalhou História da Educação Brasileira. A partir de 2010, Professora Cleide Rodrigues deixa de atuar na docência e passa a dedicar-se à Coordenação da Educação a Distância da UEPG. Nos anos de 1980 e 1990, identificamos pelos relatórios que outros docentes assumiram algumas aulas de História da Educação, em regra professores contratados temporariamente. Além disso, merece destacar que a professora Gisele Quadros Ladeira Chornobai, aprovada em concurso público em 1991, no relatório de 2002 aparece como professora de História da Educação. Em 1991 e 1992, por exemplo, ela ministrou Estrutura e Funcionamento do $1^{\circ}$. e $2^{\circ}$. Graus, Fundamentos da Educação e Psicologia da Educação. Entre 2000 e 2002, Gisele Quadros realizou mestrado em educação, na Linha de História e Historiografia da Educação da UFPR. Porém, em meados da primeira década do século XXI, ela deixou de exercer docência na UEPG.

${ }^{11}$ Em 1998, ingressou na UEPG a professora Maria Isabel Moura Nascimento, formada em Pedagogia pelo Instituto de Ciências Sociais de Americana (1992). Ela prestou concurso para Estrutura e Funcionamento do Primeiro e Segundo graus. Nesse mesmo ano, identificamos no relatório do Departamento de Educação que Maria Isabel Nascimento desenvolvia o projeto de pesquisa "As tendências epistemológicas da historiografia brasileira: análise da produção sobre a formação de professor da educação básica (1986-1996)". Em 1998, no relatório do Departamento de Educação há indicação de que ela apresentou o trabalho "A formação de professores do Ensino Médio: as tendências dominantes na historiografia brasileira" no IV Congresso Ibero-
} 
anterior, sem indicação das obras nas bibliografias. Entretanto, observamos alteração no programa de História da Educação Brasileira, pois as unidades de conteúdos ganham aspectos mais detalhados em comparação com o programa de 1990. A primeira unidade trata da educação moderna (aspectos gerais); depois são descritos os seguintes itens: implantação da educação brasileira na colônia, as revoluções europeias e os desdobramentos no Brasil, a educação brasileira no século XIX, educação na Primeira República e no período Vargas, educação na Segunda República (tramitação e aprovação da LDB, movimentos de educação popular e conscientização da população marginalizada), educação na ditadura militar, desafios da democratização sócio-educacional. Igualmente, não há indicação das obras no item referências básicas e complementares. Aqui, ao lado da contínua divisão da história política brasileira, aparecem temas e recortes específicos da educação, aspecto também presente na análise de Faria Filho e Gomes Rodrigues (2003).

A partir de 2007 entrou em vigor outra organização da disciplina. ${ }^{12}$ Em História da Educação, com carga horária de 68 horas, a ementa ficou: a educação em perspectiva histórica. História da educação: objeto, método, fontes. A educação na antiguidade clássica: Grécia e Roma. A educação medieval - a igreja como novo eixo cultural. A transição para o Renascimento. O projeto sócio-político e educacional da modernidade: libertação ou conformação. Criança, família, escola e Estado na era moderna (UEPG, 2007, p. 392). Já História da Educação Brasileira definiu-se: História e historiografia da educação. A hegemonia da educação jesuítica no Brasil (1549-1759). A crise do sistema colonial e a Reforma Pombalina. A educação escolar pública e a formação de professores no Império brasileiro. A República e os ideais educacionais da modernidade. Os trabalhadores e a

\footnotetext{
americano de História da Educação Latino-americana - Chile. Já na UEPG, Nascimento realizou doutoramento na Unicamp tratando de um objeto específico de História da Educação, a saber: A primeira escola de professores dos Campos Gerais-PR, orientada por José Claudinei Lombardi, em 2004. A partir de 2004, ela passou a trabalhar com a disciplina de História da Educação no Curso de Pedagogia. Atualmente, ela é responsável pela disciplina de História da Educação e História da Educação Brasileira (período matutino) e é professora no Programa de Pós-Graduação em Educação da UEPG.

${ }^{12}$ Em 2007, ingressou na UEPG o professor Névio de Campos. Porém, por conta de aprovação em concurso público na área de Sociologia, trabalhou com essa disciplina até 2009. A partir de 2009 passou a trabalhar com História da Educação. Formado em Filosofia pela UFPR, ele fez mestrado (2002), doutorado (2006) em Educação na linha de História e Historiografia da Educação da UFPR, pós-doutorado (2015) em História pela UFPR e pós-doutorado em Sociologia pela École des Hautes Études en Sciences Sociales (2020). Hoje, está à frente da disciplina de História da Educação (período noturno) e é professor no Programa de Pós-Graduação em Educação.
} 
educação: socialistas, libertários, comunistas. Os pioneiros da Escola Nova e a construção do sistema nacional de ensino no Brasil. O projeto educacional brasileiro na ditadura militar. A nova República e a (re) democratização educacional dos anos 80. Os anos 90 e a construção da escola cidadã. Legado educacional do século XX no Brasil: a escola pública, a feminização do magistério, a formação de professores (UEPG, 2007, p. 392). Há uma dispersão temática, ao lado da manutenção do recorte da velha história política brasileira, o que indica uma aproximação com os debates do âmbito da pesquisa dos últimos anos, deixando de atrelar história da educação apenas às ideias pedagógicas e à legislação do ensino, mas também a novas questões e objetos.

Nos programas de ensino localizamos a indicação da bibliografia básica e/ou complementar.

\begin{tabular}{|c|c|}
\hline AUTOR & OBRAS \\
\hline Gilberto Alves & $\begin{array}{l}\text { O trabalho didático na escola moderna: } \\
\text { fontes históricas - HE }\end{array}$ \\
\hline Franco Cambi & História da Pedagogia - HE \\
\hline Geraldo Francisco Filho & $\begin{array}{l}\text { A educação } \\
\text { histórico - HE }\end{array}$ \\
\hline Moacir Gadotti & História das ideias pedagógicas - HE \\
\hline $\begin{array}{l}\text { Maria E. B. Miguel e Rosa Lydia T. } \\
\text { Correa }\end{array}$ & A educação em perspectiva histórica - HE \\
\hline Cyntia Pereia de Souza & $\begin{array}{l}\text { História da Educação: } \\
\text { práticas e saberes - HE }\end{array}$ \\
\hline Marcus Levy Bencostta & $\begin{array}{l}\text { História da Educação: arquitetura e } \\
\text { espaço escolar - HEB }\end{array}$ \\
\hline Edward Carr & Que é história? - HEB \\
\hline Eric Hobsbawm & Sobre história- HEB \\
\hline Maria Cristina Menezes & Educação, memória e história - HEB \\
\hline Maria E. Blanck Miguel & $\begin{array}{l}\text { A formação do professor e a organização } \\
\text { social do trabalho - HEB }\end{array}$ \\
\hline Carlos Monarcha & $\begin{array}{l}\text { Escola Normal da Praça: o lado noturno } \\
\text { das luzes - HEB }\end{array}$ \\
\hline $\begin{array}{l}\text { Eliane M. T. Lopes; Luciano F. Filho; } \\
\text { Cynthia G. Veiga }\end{array}$ & 500 anos de educação no Brasil - HEB \\
\hline Dermeval Saviani & $\begin{array}{l}\text { História das ideias pedagógicas no Brasil } \\
\text { - HEB }\end{array}$ \\
\hline Rosa Fátima de Souza & $\begin{array}{l}\text { Templos de civilização: a implantação da } \\
\text { escola primária graduada no estado de } \\
\text { São Paulo (1890-1910) - HEB }\end{array}$ \\
\hline Maria Stephanou; Maria H. Bastos & $\begin{array}{l}\text { História e memória da educação no Brasil } \\
\text { (volumes } 1 \text { e } 3 \text { ) - HEB }\end{array}$ \\
\hline Etelvina M. C. Trindade & $\begin{array}{l}\text { Clotildes ou marias: mulheres de Curitiba } \\
\text { na Primeira República - HEB }\end{array}$ \\
\hline
\end{tabular}

Fonte: O autor (2020). 
Por fim, a última alteração nas ementas aconteceu em $2012^{13}$. História da Educação ficou assim: História e História da Educação. A educação nos contextos da Antiguidade Clássica, dos Períodos Medieval, Moderno e Contemporâneo, enfatizando uma abordagem das temáticas relacionadas às ideias educativas e/ou pedagógicas e a organização das instituições de ensino. E História da Educação Brasileira definiu-se: História e historiografia da educação brasileira. A educação nos diferentes contextos da História da Brasil e Paraná (séculos XVI-XXI), privilegiando discussões dos variados temas e problemas referentes à história das ideias educativas e/ou pedagógicas e aos modelos e/ou projetos educacionais escolares e não escolares (UEPG, 2013, p. 352). Essa contemplou a organização da seguinte bibliografia básica.

\begin{tabular}{|c|c|}
\hline AUTOR & OBRAS \\
\hline Philippe Ariès & $\begin{array}{l}\text { História social da criança e da família - } \\
\text { HE }\end{array}$ \\
\hline Georges Duby & $\begin{array}{l}\text { História da vida privada (da Europa } \\
\text { feudal à Renascença) - HE }\end{array}$ \\
\hline Leni Dornelles & $\begin{array}{l}\text { Infâncias que nos escapam: da criança } \\
\text { na rua à criança cyber - HE }\end{array}$ \\
\hline $\begin{array}{l}\text { Marcos C. Freitas e Moysés Kuhlmann } \\
\text { Junior }\end{array}$ & $\begin{array}{l}\text { Os intelectuais na história da infância - } \\
\mathrm{HE}\end{array}$ \\
\hline David Hamilton & $\begin{array}{l}\text { Notas de lugar nenhum: sobre os } \\
\text { primórdios da escolarização moderna } \\
\text { (artigo) - HE }\end{array}$ \\
\hline Eric Hobsbawm & $\begin{array}{l}\text { Nações e nacionalismo desde } 1780 \text { : } \\
\text { programa, mito e realidade - HE }\end{array}$ \\
\hline Julia Varela e Fernando Alvarez-Uria & A maquinaria escolar (artigo) - $\mathrm{HE}$ \\
\hline Paul Veyne & $\begin{array}{l}\text { História da vida privada (do Império } \\
\text { Romano ao Ano Mil) - HE }\end{array}$ \\
\hline Peter Burke & $\begin{array}{l}\text { Escrita da história: novas abordagens - } \\
\text { HEB }\end{array}$ \\
\hline Franco Cambi & História da Pedagogia - HE/HEB \\
\hline
\end{tabular}

\footnotetext{
${ }^{13}$ Em 2011, ingressou na UEPG a professora Maria Julieta Weber Cordova por meio de concurso público na área de Fundamentos da Educação. Ela é formada em História (1995), Especialista em História e Região (1999), Mestre em Educação (2003) pela UEPG. Em sua pesquisa de mestrado desenvolveu a dissertação "Produção da Memória e o Patrimônio Tombado na Lapa/PR: perspectivas para o currículo escolar". Em seu doutorado, realizado no Programa de Pós-Graduação em Sociologia (2009), defendeu a tese "Tinguis, Pioneiros e Adventícios: o discurso regional autorizado de formação social e histórica paranaense". Ela é pós-doutora em História pela UFPR (2019). A professora Julieta Cordova passou a compor o grupo de professores de História da Educação, a partir de 2012. Ela é responsável por História da Educação Brasileira (período noturno) e professora no Curso de Mestrado em História e no Programa de Pós-Graduação em Educação da UEPG.
} 


\begin{tabular}{|l|l|}
\hline José Murilo de Carvalho & $\begin{array}{l}\text { A construção da ordem: a elite política } \\
\text { imperial. Teatro das sombras: a política } \\
\text { imperial - HEB }\end{array}$ \\
\hline Boris Fausto & História do Brasil - HEB \\
\hline Geraldo Francisco Filho & $\begin{array}{l}\text { A educação brasileira no contexto } \\
\text { histórico - HEB }\end{array}$ \\
\hline Dermeval Saviani & $\begin{array}{l}\text { História das ideias pedagógicas no Brasil } \\
- \text { HEB }\end{array}$ \\
\hline $\begin{array}{l}\text { Maria Stephanou e Maria Helena } \\
\text { Bastos }\end{array}$ & $\begin{array}{l}\text { Histórias e memórias da educação no } \\
\text { Brasil (3 volumes) - HEB }\end{array}$ \\
\hline
\end{tabular}

Fonte: O autor (2020).

Nesse longo percurso, observa-se uma forte continuidade dos conteúdos, em especial atrelados aos tradicionais recortes temporais da história ocidental (Antiga, Média, Moderno e Contemporâneo) e à tradicional divisão política brasileira (Colônia, Império e República) ${ }^{14}$. Há, na verdade, algumas alterações com a inclusão de temáticas específicas da educação, como, por exemplo, feminização do magistério, criança e infância, formação de professores. Essa tendência se aproxima dos estudos que trataram do ensino de História da Educação em outras universidades brasileiras, como, por exemplo, a produção de Claudemir de Quadros (2011, p. 29).

Outro aspecto a ser destacado diz respeito à bibliografia utilizada. De 1975 até 1987 se observa uma presença marcante dos tradicionais manuais de História da Educação. A partir da mudança de 1990 não aparecem as bibliografias nos programas da disciplina. No entanto, a discriminação dos conteúdos ainda é semelhante ao momento anterior, sugerindo uma relação atrelada aos sumários dos manuais de História da Educação. Essa observação indica que a reverberação dos manuais avançou os anos de 1990, o que demanda outras pesquisas a partir de outras fontes para sustentar essa tendência. Em relação ao uso de manuais de História da Educação no Brasil há vários estudos à disposição, entre os quais destacamos as pesquisas de Aline de Morais Limeira Pasche (2014), José Cláudio Sooma Silva e Marta Regina Favaro (2014), Roni de Menezes (2014), Décio Gatti

\footnotetext{
${ }^{14}$ Há uma forte discussão a respeito dessa dependência do ensino de história da educação em relação aos acontecimentos da velha história política. É elucidativo o artigo Educação brasileira e a sua periodização: vestígios de uma identidade disciplinar, de Bruno Bontempi Junior. (2003) que mostra como Laerte Ramos de Carvalho liderou um grupo de pesquisadores entre os anos 1950-1960 que produziu reflexões sobre outros critérios para estudar a educação brasileira, além dos recortes políticos (Colônia, Império e República).
} 
Junior (2011), Bruno Borges e Décio Gatti Junior (2010), José Carlos Araújo, Betânia Ribeiro e Sauloéber Souza (2011), Thais Fonseca (2011). Já a partir das referências de 2007 (quadros 4 e 5) observa-se uma diversificação de obras. Em regra, são obras mais específicas. No entanto, ainda há livros que apresentam uma visão geral da educação, privilegiando um retrato da história da pedagogia e história das ideias pedagógicas.

\section{História da Educação na UEPG e no Brasil: algumas conexões}

A História da Educação foi incorporada como disciplina de formação de professores no século XIX, na Europa, e no final da década de 1920 (Escola Normal) e no final da década de 1930 (Curso de Pedagogia), no Brasil. Conforme Décio Gatti Junior (2006, p. 108), "na Europa, desde o final do século XIX, há cursos de História da Educação em universidades e escolas normais, experiência que se dissemina pelo mundo e que inclui o Brasil, especialmente sua escola normal". Entretanto, no caso do Brasil, segundo indica Gatti Junior (2006, p. 109), no último quartel do século XIX, "apesar de incluir as disciplinas História Universal e História e Geografia do Brasil, ainda não traz a História da Educação como componente curricular".

O movimento da Escola Nova, capitaneado por um conjunto de educadores e cientistas sociais brasileiros, propugnou a constituição da ciência da educação. Nesse sentido, algumas ciências passaram a constituir os modelos por excelência para consolidar a especificidade teórica e metodológica do campo investigativo. A História da Educação não teve o mesmo status acadêmico e científico para compor o quadro das ciências auxiliares da educação, figurando muito mais como disciplina formativa nas escolas normais e nas faculdades de educação ou de filosofia. Ou seja, conforme Gatti Junior (2006, p. 110), a disciplina de História da Educação foi introduzida, "antes mesmo da criação de uma estrutura de pesquisa em educação e, de modo particular, da conjugação de esforços efetivos da pesquisa em História da Educação".

Na acepção de Warde (1990, p. 8),

a História da Educação é filha tardia de aportes múltiplos à educação; não é incluída, entre as ciências auxiliares, com o mesmo 
escopo das matriciais; se não tem nada a oferecer para que o presente seja objeto de controle, a sua utilidade é pensada como de natureza disciplinar.

A identidade da História da Educação como disciplina e não como área de investigação deu um caráter diferenciado ao campo de formação de professores. Ao lado da filosofia da educação, ela deveria "responder à necessidade de os futuros professores cogitarem do dever ser educacional, dos valores humanos mais elevados a serem preservados e despertados pela prática da educação" (WARDE, 1990, p. 8).

O modo pelo qual ela foi incluída no quadro disciplinar implicou uma formatação pragmática de seu ensino. Conforme sintetiza Gatti Junior (2006, p. 111), "a educação era vista como articuladora da pesquisa e do ensino, mas, dada às urgências, com papel eminentemente utilitário e prático". Nem mesmo a filosofia e a história da educação escaparam daquela condição que conformava o campo de formação de professores. Tal afirmação é sustentada por Warde (1990, p. 9): "primeiro, sofreu a pragmatização moral, porque dela havia de se tirar alguma lição, algum ensinamento doutrinário". Mais tarde, "em torno das décadas de 50 e 60, quando começaram a surgir, efetivamente, estudos históricos relativos à educação brasileira, a pragmatização já instaurada foi secularizada" (WARDE, 1990, p. 9). A rigor, a constituição da História da Educação nos cursos de formação de professor e pedagogo guardou uma particularidade: caráter eminentemente disciplinar. Tal característica resultou em

uma marca que lhe é conformadora: a de ter nascido para ser útil e para ter eficácia medida não pelo que é capaz de explicar e interpretar dos processos históricos objetivos da educação, mas pelo que oferece de justificativas para o presente (WARDE, 1990, p. 9).

Em interlocução com essa análise, Marta Carvalho (2004) discute as razões que determinaram tal caracterização da História da Educação. Ou melhor, que fatores explicariam essa identidade da História da Educação? De acordo com Carvalho, a concepção de história incorporada pelo grupo do movimento pela Escola Nova estava vinculada ao Instituto Histórico e Geográfico do Brasil (IHGB), no qual se compreendia história como mestra da vida. Nesse sentido, os 
conhecimentos históricos deveriam ser compreendidos como elementos fundamentais de constituição da nação e do sentimento de nacionalidade.

Grande parte dos autores de manuais de História da Educação que escreveram para atender a demanda das antigas escolas normais (Institutos de Educação) e das Faculdade de Educação/Filosofia estavam associados ao IHGB, portanto, expressavam a concepção de história como mestra da vida. Nesses termos, o papel dessa disciplina consistia em conformar os corações e as mentes dos professores para plasmar nas almas dos pequenos brasileiros os sentimentos de nacionalidade. Na definição de Carlos Eduardo Vieira e Roberlayne Roballo, a História da Educação cumpria três papeis:

Formação moral e cívica dos professores; formação pedagógica, através do reconhecimento dos acertos e dos erros do passado; e, por fim, produção da memória do grupo de intelectuais que liderava o projeto de renovação do pensamento e das práticas educacionais. (VIEIRA; ROBALLO, 2007, p. 255).

Conforme Décio Gatti Junior (2006, p. 110), "na esteira da afirmação da escola normal são produzidos os manuais escolares de História da Educação, que seriam amplamente utilizados pelos normalistas". A tônica dos manuais, na interpretação de Gatti Junior (2006, p. 110), assinala "um afastamento dos arquivos com a cristalização de uma escrita moralizadora, restringindo-se a História da Educação à função de disciplina formadora".

Esse quadro começou a ser relativizado a partir da década de 1950 com as pesquisas em História da Educação realizadas pela Faculdade de Educação da Universidade de São Paulo, coordenadas por Laerte Ramos de Carvalho, bem como com a criação do Centro Nacional de Pesquisa Educacional e dos Centros Regionais. Esses dois espaços visavam, na compreensão de Warde, a "um projeto de construção de uma história da educação brasileira, autônoma, apoiada em levantamentos documentais originais, capaz de recobrir o processo de desenvolvimento do sistema público de ensino" (WARDE, 1998, p. 93). Entretanto, guardadas as contribuições dessas iniciativas, Miram Warde (1998, p. 93) considera que tais fenômenos não foram capazes de "dissolver as marcas genéticas da história da educação produzida nos nossos meios educacionais".

Outro movimento que contribuiu para relativizar a marca disciplinar da História da Educação foi a implantação da Pós-Graduação na década de 1970 . Na 
argumentação de Warde, os limites teóricos e institucionais determinaram a própria identidade disciplinar da História da Educação. Marta Carvalho (2004, p. 380) reafirma essa tese ao sustentar que:

[o]s moldes em que se deu o atrelamento originário da disciplina a objetivos institucionais de formação de professores e pedagogos dificultaram, até muito recentemente, a sua constituição como área de investigação historiográfica capaz de se autodelimitar e de definir, a partir de sua própria prática, questões, temas e objetos.

A constituição da História da Educação como campo de pesquisa ganhou contornos significativos a partir da experiência da USP, na década de 1950, e da implantação da Pós-Graduação no Brasil. Entre o final da década de 1980 e início da década de 1990, a História da Educação intensificou a interlocução com as discussões teóricas e metodológicas da História, particularmente História Cultural. Tal movimento implicou a multiplicação de pesquisas de natureza histórica, redundando na formação de pesquisadores e professores de História da Educação.

Esse movimento geral pode ser observado na organização da História da Educação na UEPG, particularmente ao observarmos a forte presença de manuais didáticos no rol de referências, conforme evidenciam os quadros 2 e 3 . De modo semelhante, é possível observar que, no período mais recente, há uma aproximação com a produção acadêmica do campo da História da Educação, particularmente com as obras produzidas por pesquisadores dos programas de pós-graduação, como atestam as referências descritas nos quadros 4 e 5 .

\section{Considerações finais}

Este artigo integra o conjunto de produção que tem tratado do ensino de História da Educação nas licenciaturas, notadamente no Curso de Pedagogia. Há muitas pesquisas, conforme indicamos na primeira nota de rodapé. As formas de análises são diferenciadas, chamando atenção os estudos específicos para inventariar as experiências de ensino em cada instituição universitária brasileira. Nesse sentido, esta narrativa inscreve-se nessa modalidade de investigação, pois teve a pretensão de explicitar a organização do ensino de História da Educação na UEPG, no período circunscrito entre 1963 e 2012. 
As possibilidades de abordagem da trajetória da História da Educação no âmbito do ensino na UEPG são variadas. Diante disso, a delimitação privilegiou um olhar sobre a denominação e a carga horária, as ementas, os programas e a bibliografia indicada. Outras possibilidades de análises ficam abertas, tomando outras fontes para ampliar o escopo interpretativo. Assim, é fundamental que outras pesquisas tratem deste problema na UEPG, buscando aprofundar a discussão deste texto.

A primeira contribuição deste artigo diz respeito à organização do ensino de história da educação, desde 1963. Entre 1963 e 2012 (última reforma do curso de Pedagogia), ela alterou a sua nomenclatura e sua carga horária. Além disso, observa-se uma presença marcante de manuais no processo de seu ensino, característica semelhante com as demais faculdades e universidades brasileiras, conforme evidenciam os quadros 2 e 3 . Ademais, vê-se um processo de alteração nas ementas e nos programas nas duas últimas décadas, indicando aproximações entre as experiências do campo de pesquisa e ensino, de acordo com os dados dos quadros 3 e 4 . Nesse aspecto, essa tendência está associada à situação de que os professores responsáveis pelo ensino de História da Educação estão vinculados com pesquisas em temáticas dessa área do conhecimento e atuam na pósgraduação. Até os anos de 1990, a organização do seu ensino expressava fortes marcas de diretrizes dos manuais, de recortes da história política, de obras que fazem uma leitura panorâmica e cronológica da história da educação. A partir dos anos dois mil se observa uma mudança, incluindo-se obras com características mais específicas do campo de pesquisa da História da Educação, muito embora estejam presentes duas obras panorâmicas, a saber, História da Pedagogia (Cambi) e História das ideias pedagógicas do Brasil (Saviani).

Portanto, nesta leitura de amplo espectro é possível observar que a História da Educação manteve interlocução com os manuais produzidos para o seu ensino nos cursos de formação de professores, assim como indicar a aproximação da experiência do seu ensino com a produção acadêmica das últimas décadas, fator relacionado com a ampliação das pesquisas nessa área de conhecimento e formação de novos pesquisadores e docentes. 


\section{Referências}

ACOSTAS, Felicitas. Ensinar história da educação: reflexões em torno de uma proposta. História da Educação, Porto Alegre, v. 21, n. 52, p. 295-311, 2017.

ARAÚJO, José Carlos Souza; RIBEIRO, Betânia de Oliveira Laterza; SOUZA, Sauloéber Társio de. Haveria uma historiografia educacional brasileira expressa pelos manuais didáticos publicados entre 1914 e 1972? In: CARVALHO, Marta Maria Chagas de; GATTI JUNIOR, Décio (org.). O ensino de história da educação. Vitória: EDUFES, 2011. p. 95-144.

AZEVEDO, Regina Quintanilha; ISMÉRIO, Clarisse; SILVEIRA, Marilene Vaz. Apontamentos sobre a disciplina história da educação na Universidade da Região da Campanha - URCAMP (1959-2001). História da Educação, Pelotas, n. 19, p. 275-294, abr. 2006.

BASTOS, Maria Helena Camara; BENCOSTTA, Marcus Levy Albino; CUNHA, Maria Teresa Santos. Uma cartografia da pesquisa em história da educação na região sul: Paraná, Santa Catarina, Rio Grande do Sul (1980-2000). Pelotas: Seiva, 2004.

BASTOS, Maria Helena Camara; BUSNELLO, Fernanda de Bastani; LEMOS, Elizandra Ambrosio. Disciplina história da educação no curso de pedagogia da Pontifícia Universidade Católica do Rio Grande do Sul (1942-2002). História da Educação, Pelotas, n. 19, p. 181-212, abr. 2006.

BENCOSTTA, Marcus Levy Albino; VIDAL, Diana Gonçalves. A historiografia da educação paranaense no cenário da História da Educação Brasileira: 10 anos de pesquisa na Universidade Federal do Paraná (1999-2008). Educar em Revista, Curitiba, n. 38, p. 295-315, set./dez. 2010.

BONTEMPI JUNIOR, Bruno. A educação brasileira e a sua Periodização: vestígio de uma identidade disciplinar. Revista Brasileira de História da Educação, Maringá, n. 5, p. 43-68, jan./jun. 2003.

BONTEMPI JUNIOR, Bruno. O ensino e a pesquisa em história da educação brasileira na cadeira de filosofia e história da educação (1933-1962). História da Educação, Pelotas, n. 21, p. 79-105, 2007.

BORGES, Bruno Gonçalves; GATTI JUNIOR, Décio. O ensino de história da educação na formação de professores no Brasil atual. Revista Histedbr Online, Campinas, n. 40, p. 24-48, 2010.

CAMPOS, Névio de. Lugar da história da educação na formação do professor/pedagogo. Educação Unisinos, São Leopoldo, v. 15, n. 2, p. 95-104, maio/ago. 2011.

CAMPOS, Névio de; SOUZA, Eliezer Felix de. Ensino superior nas páginas do Diário dos Campos (1947-1950). Educar em Revista, Curitiba, p. 273-290, 2016. 
CARVALHO, Marta Maria Chagas de. Por entre restos de memória: um relato sobre o ensino de História da Educação no Curso de Pedagogia da Faculdade de Educação da USP (1971-1997). In: CARVALHO, Marta Maria Chagas de; GATTI JUNIOR, Décio (org.). O ensino de história da educação. Vitória: EDUFES, 2011. p. 277-304.

CARVALHO, Marta Maria Chagas de. Revisitando a historiografia educacional brasileira. In: MENEZES, Maria Cristina (org.). Educação, memória, história: possibilidades, leituras. Campinas: Mercado de Letras, 2004. p. 375-401.

CRUZ, Giseli Barreto da. Curso de pedagogia no Brasil - história e formação com pedagogos. Rio de Janeiro: Wak Editora, 2011.

DALLABRIDA, Norberto. Qual história da educação ensinar? In: CARVALHO, Marta Maria Chagas de; GATTI JUNIOR, Décio (org.). O ensino de história da educação. Vitória: EDUFES, 2011. p. 337-362.

ESQUINSANI, Rosimar Serena Siqueira. A história da educação no curso de pedagogia da Universidade de Passo Fundo: aportes na história recente em busca de novas perspectivas. História da Educação, Pelotas, n. 19, p. 253-261, abr. 2006.

FARIA FILHO, Luciano Mendes de; RODRIGUES, José Roberto Gomes. A história da educação programada: uma aproximação da história da educação ensinada nos cursos de pedagogia em Belo Horizonte. Revista Brasileira de História da Educação, São Paulo, n. 6, p. 159-176, 2003.

FONSECA, Thais Nivia de Lima e. O período colonial nos manuais de história da educação Brasileira. In: CARVALHO, Marta Maria Chagas de; GATTI JUNIOR, Décio (org.). O ensino de história da educação. Vitória: EDUFES, 2011. p. 363387.

GATTI JUNIOR, Décio. A história do ensino de história da educação no Brasil: aspectos teórico-metodológicos de uma pesquisa (1930-2000). História da Educação, Pelotas, v. 12, n. 26, p. 219-246, 2008.

GATTI JUNIOR, Décio. Estudo sobre o processo de constituição do ensino e da pesquisa em história da educação no Brasil (séculos XIX e XX). In: MORAIS, Christianni Cardoso; PORTES, Écio Antônio; ARRUDA, Maria Aparecida (org.). História da educação: ensino e pesquisa. Belo Horizonte: Autêntica, 2006. p. 107-123.

GATTI JUNIOR., Décio. Intelectuais e circulação internacional de ideias na construção da disciplina de História da Educação no Brasil (1955-2008). In: CARVALHO, Marta Maria Chagas de; GATTI JUNIOR, Décio (org.). O ensino de história da educação. Vitória: EDUFES, 2011. p. 95-144.

HARTOG, François. Os antigos, o passado e o presente. Brasília: Editora Universidade de Brasília, 2003. 
KOSELLECK, Reinhart. Futuro-passado: contribuição à semântica dos tempos históricos. Rio de Janeiro: Contraponto: Editora PUC-RJ, 2006.

LE GOFF, Jacques. A história deve ser dividida em pedaços?. São Paulo: UNESP, 2014.

MENDEZ, Jorgelina. Entre Europa e América: a escrita da história da educação na Argentina por Lorenzo Luzuriaga. Revista Brasileira de História da Educação, Maringá, v. 14, n. 3, p. 235-256, set./dez. 2014.

MENEZES, Roni Cleber Dias de. Circuito e fronteiras da escrita da história da educação na Ibero-America: experiência de escrita de Lorenzo Luzuriaga na Espanha e na Argentina e sua Apropriação no Brasil. Revista Brasileira de História da Educação, Maringá, v. 14, n. 3, p. 257-280, set./dez. 2014.

MONARCHA, Carlos. História da educação brasileira: formação do campo. Ijuí: Editora Unijuí, 2005.

MORAIS, Christianni Cardoso; PORTES, Écio Antônio; ARRUDA, Maria Aparecida (org.). História da educação: ensino e pesquisa. Belo Horizonte: Autêntica, 2006.

NUNES, Clarice. A disciplina história da educação na formação de professores: desafios contemporâneos. História da Educação, Pelotas, n. 19, p. 173-180, abr. 2006.

NUNES, Clarice. Ensino e historiografia da educação: problematização de uma hipótese. Revista Brasileira de Educação, São Paulo, n. 1, p. 67-79. 1996.

ORTH, Miguel Alfredo. A disciplina de História da Educação na Faculdade e no Centro Universitário La Salle. História da Educação, Pelotas, n. 19, p. 229-242, abr. 2006.

PASCHE, Aline de Morais Limeira. A história da educação por Thomas Ransom Giles. Revista Brasileira de História da Educação, Maringá, v. 14, n. 3, p. 205233, set./dez. 2014.

QUADROS, Claudemir de. Aspectos da trajetória da disciplina História da Educação no curso de pedagogia do Centro Universitário Franciscano de Santa Maria: temas clássicos e ordem cronológica. História da Educação, Pelotas, n. 19, p. 213-228, abr. 2006.

QUADROS, Claudemir de. Ensino com pesquisa, educação digital e formação de professores: possibilidades de ensinar e aprender acerca da história da educação. In: CARVALHO, Marta Maria Chagas de; GATTI JUNIOR, Décio (org.). O ensino de história da educação. Vitória: EDUFES, 2011. p. 17-46.

QUEIROZ, Zuleide Fernandes de. Ensinando história da educação, formando professores-pesquisadores: o ensino da história da educação no curso de pedagogia da Universidade Regional do Cariri. In: CARVALHO, Marta Maria 
Chagas de; GATTI JUNIOR, Décio (org.). O ensino de história da educação. Vitória: EDUFES, 2011. p. 389-405.

RODRIGUES, José Roberto. O ensino de história da educação: um olhar reflexivo a partir da análise de planos e programas curriculares. In: CARVALHO, Marta Maria Chagas de; GATTI JUNIOR, Décio (org.). O ensino de história da educação. Vitória: EDUFES, 2011. p. 145-174.

SANTIAGO, Anna Rosa Fontella. O ensino de história da educação na UNIJUI. História da Educação, Pelotas, n. 19, p. 243-251, abr. 2006.

SAVIANI, Dermeval. Ensino, pesquisa e organização na formação do campo da história da educação brasileira. In: MONARCHA, Carlos (org.). História da educação brasileira: formação do campo. Ijuí: Unijui, 2005a. p. 47-114.

SAVIANI, Dermeval. Pedagogia: o espaço da educação na universidade. Cadernos de Pesquisa, São Paulo, v. 37, n. 130, p. 99-134, jan./abr. 2007.

SAVIANI, Dermeval. Reflexões sobre o ensino e a pesquisa em história da educação. In: GATTI JUNIOR., Décio; INÁCIO FILHO, Geraldo (org.). História da educação em perspectiva: ensino, pesquisa, produção e novas investigações. Campinas: Autores Associados, 2005b. p. 7-31.

SILVA, José Cláudio Sooma; FAVARO, Marta Regina Gimenez. Paul Monroe e a circulação de uma modalidade narrativa para se pensar e ensinar as histórias da educação. Revista Brasileira de História da Educação, Maringá, v. 14, n. 3, p. 181-204, set./dez. 2014.

SOUZA, Audrey Pietrobelli. Trajetória da psicologia da educação no curso de pedagogia da UEPG (1962-2012): conformação e consolidação do campo de conhecimento. 2017. Tese (Doutorado em Educação) - Universidade Estadual de Ponta Grossa, Ponta Grossa, 2017.

SOUZA, Sauloéber Tarsio de; RIBEIRO, Betânia de Oliveira de. Ensino de História da Educação no Brasil: reflexões sobre o perfil de professores e suas metodologias. História da Educação, Porto Alegre, v. 16, n. 36, p. 60-76, 2012.

STEPHANOU, Maria. O ensino de história da educação na história da Faculdade de Educação da UFRGS: primeiras aproximações. História da Educação, Pelotas, v. 10, n. 19, p. 293-300, 2006.

TAMBARA, Elomar. História da educação no curso de pedagogia da Universidade Federal de Pelotas. História da Educação, Pelotas, v. 10, n. 19, p. 301-310, 2006.

UEPG - UNIVERSIDADE ESTADUAL DE PONTA GROSSA. Faculdade Estadual de Filosofia, Ciências e Letras de Ponta Grossa. Relatórios. Ponta Grossa: UEPG, 1964. 
UEPG - UNIVERSIDADE ESTADUAL DE PONTA GROSSA. Faculdade Estadual de Filosofia, Ciências e Letras de Ponta Grossa. Relatórios. Ponta Grossa: UEPG, 1965.

UEPG - UNIVERSIDADE ESTADUAL DE PONTA GROSSA. Faculdade Estadual de Filosofia, Ciências e Letras de Ponta Grossa. Relatórios. Ponta Grossa: UEPG, 1967.

UEPG - UNIVERSIDADE ESTADUAL DE PONTA GROSSA. Pró-Reitoria de Graduação. Divisão de Ensino. Programa de disciplinas. Ponta Grossa: UEPG, 1973.

UEPG - UNIVERSIDADE ESTADUAL DE PONTA GROSSA. Pró-Reitoria de Graduação. Divisão de Ensino. Programa de disciplinas. Ponta Grossa: UEPG, 1979.

UEPG - UNIVERSIDADE ESTADUAL DE PONTA GROSSA. Pró-Reitoria de Graduação. Divisão de Ensino. Programa de disciplinas. Ponta Grossa: UEPG, 1987.

UEPG - UNIVERSIDADE ESTADUAL DE PONTA GROSSA. Pró-Reitoria de Graduação. Divisão de Ensino. Programa de disciplinas. Ponta Grossa: UEPG, 1989.

UEPG - UNIVERSIDADE ESTADUAL DE PONTA GROSSA. Pró-Reitoria de Graduação. Divisão de Ensino. Programa de disciplinas. Ponta Grossa: UEPG, 1991.

UEPG - UNIVERSIDADE ESTADUAL DE PONTA GROSSA. Pró-Reitoria de Graduação. Divisão de Ensino. Programa de disciplinas. Ponta Grossa: UEPG, 2007.

UEPG - UNIVERSIDADE ESTADUAL DE PONTA GROSSA. Pró-Reitoria de Graduação. Divisão de Ensino. Programa de disciplinas. Ponta Grossa: UEPG, 2013.

UEPG - UNIVERSIDADE ESTADUAL DE PONTA GROSSA. Setor de Ciências Humanas, Letras e Artes. Relatórios. Ponta Grossa: UEPG, 1972.

UEPG - UNIVERSIDADE ESTADUAL DE PONTA GROSSA. Setor de Ciências Humanas, Letras e Artes. Relatórios. Ponta Grossa: UEPG, 1975.

UEPG - UNIVERSIDADE ESTADUAL DE PONTA GROSSA. Setor de Ciências Humanas, Letras e Artes. Relatórios. Ponta Grossa: UEPG, 1977.

UEPG - UNIVERSIDADE ESTADUAL DE PONTA GROSSA. Setor de Ciências Humanas, Letras e Artes. Catálogo geral. Ponta Grossa: UEPG, 1980.

UEPG - UNIVERSIDADE ESTADUAL DE PONTA GROSSA. Setor de Ciências Humanas, Letras e Artes. Catálogo geral. Ponta Grossa: UEPG, 1985. 
UEPG - UNIVERSIDADE ESTADUAL DE PONTA GROSSA. Setor de Ciências Humanas, Letras e Artes. Catálogo geral. Ponta Grossa: UEPG, 1990.

UEPG - UNIVERSIDADE ESTADUAL DE PONTA GROSSA. Setor de Ciências Humanas, Letras e Artes. Relatórios. Ponta Grossa: UEPG, 1991.

UEPG - UNIVERSIDADE ESTADUAL DE PONTA GROSSA. Setor de Ciências Humanas, Letras e Artes. Relatórios. Ponta Grossa: UEPG, 1992.

UEPG - UNIVERSIDADE ESTADUAL DE PONTA GROSSA. Setor de Ciências Humanas, Letras e Artes. Catálogo geral. Ponta Grossa: UEPG, 1997.

UEPG - UNIVERSIDADE ESTADUAL DE PONTA GROSSA. Setor de Ciências Humanas, Letras e Artes. Relatórios. Ponta Grossa: UEPG, 1998.

UEPG - UNIVERSIDADE ESTADUAL DE PONTA GROSSA. Setor de Ciências Humanas, Letras e Artes. Relatórios. Ponta Grossa: UEPG, 1999.

UEPG - UNIVERSIDADE ESTADUAL DE PONTA GROSSA. Setor de Ciências Humanas, Letras e Artes. Relatórios. Ponta Grossa: UEPG, 2000.

UEPG - UNIVERSIDADE ESTADUAL DE PONTA GROSSA. Setor de Ciências Humanas, Letras e Artes. Relatórios. Ponta Grossa: UEPG, 2001.

UEPG - UNIVERSIDADE ESTADUAL DE PONTA GROSSA. Setor de Ciências Humanas, Letras e Artes. Relatórios. Ponta Grossa: UEPG, 2002.

UEPG - UNIVERSIDADE ESTADUAL DE PONTA GROSSA. Setor de Ciências Humanas, Letras e Artes. Catálogo geral. Ponta Grossa: UEPG, 2007.

VALLE, Hardalla Santos do. Fontes no ensino de história da educação: uma discussão sobre construção do conhecimento. História \& Ensino, Londrina, v. 18, n. 1, p. 173-186, jan./jun. 2012.

VIDAL, Diana Gonçalves; FARIA FILHO, Luciano. História da Educação no Brasil: a constituição histórica do campo (1880-1970). Revista Brasileira de História, São Paulo, v. 23, n. 45, p. 37-70, 2003.

VIEIRA, Carlos Eduardo; ROBALLO, Roberlayne de Oliveira Borges. História e história da educação no projeto de formação de professores na década de 30 no Brasil: problematizando as noções de Afrânio Peixoto. Inter-Ação, Goiânia, v. 32, n. 2, p. 243-259, 2007.

WARDE, Mirian Jorge. Contribuições da história para a educação. Em Aberto, Brasília, v. 9, n. 47, p. 1-11, 1990.

WARDE, Mirian Jorge. Questões teóricas e de método: a história da educação nos marcos de uma história das disciplinas. In: SAVIANI, Dermeval; LOMBARDI, José 
Claudinei; SANFELICE, José Luiz (org.). História e história da educação: o debate teórico metodológico atual. Campinas: Autores Associados, 1998. p. 88-99.

WARDE, Mirian Jorge. Brincando nos campos do senhor: anotações para uma história da formação dos professores e do ensino da História da Educação no Brasil. In: CARVALHO, Marta Maria Chagas de; GATTI JUNIOR, Décio (org.). $O$ ensino de história da educação. Vitória: EDUFES, 2011. p. 305-335.

WERLE, Flávia Obino Corrêa; CORSETTI, Berenice. História da Educação e a formação do professor na Unisinos. História da Educação, Pelotas, n. 19, p. 263274, abr. 2006.

Recebido em 11 de Junho de 2018 Aprovado em 28 de Outubro de 2020 